\title{
- Error Estimates in Generalized Trigonometric Hölder-Zygmund Norms
}

\author{
J. Prestix and S. Prössdorf
}

Dedicated to Professor Lothar Berg on the occusion of his 60th birthday

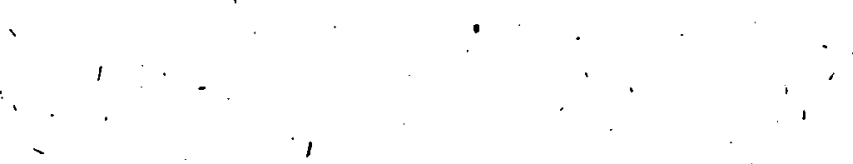

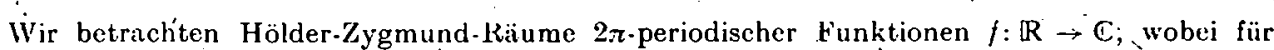
die $r$-te $A$ bleitung die $k$-te Differenz mit Schrittweite $h$ in der $L^{p}$. oder $C$-Norm durch eine Funktion $\omega(h)$ vom Modul-Typ beschränkt ist. Für die Fourier-Summe und ähnliche Approximationsprozesse erhalten wir Fehlerabschätzungen in dazugehörigen Hölder-Zygmund-Normen, falls die Glattheit von $f$ dirch weitere Hölder-Zygmund-Bedingungen gegeben ist. Die Konvergenzgeschwindigkeit" älst sich auch im allgemeinen Fall in cinfacher Weise angeben. Dies gestattet die Formulierung von Sätzen vom.Jackson-Týp für diese Banachräume: Außerdem lassen sich die Konštanten in diesen Abschätzungen explizit berechnen.

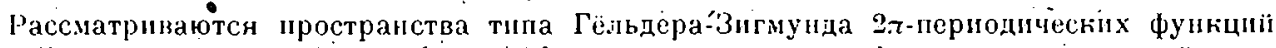
$f: \mathbb{R} \rightarrow \mathbb{C}$ таких, что $L^{\dot{p}}$-или $C$-норма $k$-той разности с нагом $h$ от $r$-той проізводної огра-

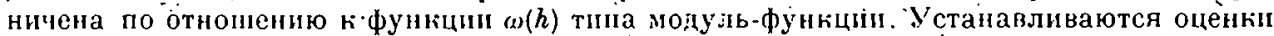
погрешности для частной суммы фурье и для цругих процессов анироксимации в соответствующих пормах Гёльдера-Знгмунда, если гіанкость $f$ защана и терминах других

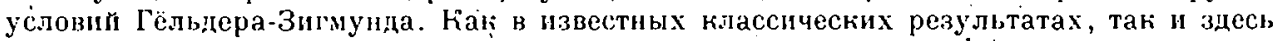
скорость сходиности выражается простын образом. Әто позвоэлет формулировать

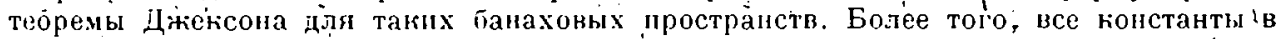
соотнетстиуюіцих ощенах вычнсляются нвым образом.

We consider Hölder;Zygmund spaces of $2 z$-periodic functions $f: \mathbb{R} \rightarrow \mathbb{C}$, where the $k$-th difference with step-size $h$ of the $r$-th derivative in the $L^{p}$ or $C$-norm is bounded by a modulustype function $\omega(h)$. For the Fourier sum and related approximation processes we investigate error-estimates in corresponding Hölder-Zygmund norms if the smoothness of $f$ is given by other Hölder-Zygmund conditions. The convergence order for the general case can be formulated in a simple minner. 'Fhis allows us to state also Jackson-type theorems for such Banach spaces. Moreover, we give explicit values for the constants appearing in these estimates.

\section{Introduction}

Convergence results in Hölder-Zygmund norms for given trigonometric approximation processes play an important role in the approximate solution of singular. integral equations (see $[11,12]$ ). In particular, the convergence order in such Hölder norms for the Fourier sum and the interpolatory polynomial on equidistant nodes has been treated in a series of papers in the last 15 years: In this connection, we mention Lisinder [4], Strýśsk r [14], Krotov [3], Sick fl [13] and the author's [7-12]. However, these papers contain in detail only the case of the classical growth condition $h^{a}$. for the difference term.

The aim of this paper is to prove approximation results in Höldcr norms based on general modulus-type functions $\omega$. Note that our approach does not need essential restrictions on $\omega$. In this direction our results generalize theorems obtained in [4], where $\omega$ has to fulfil very delicate inequalities. Here we establish an easier and more general convergence condition which allows us also to find the order of convergence. 
- Since the modulus of continuity based on the first difference does not describe' the best approximation completely, we use higher differences. First results in such HölderZygmund norms are contained in $[5,6]$.

In detail, we consider the Fourier sum and its de la Vallée Poussin means. However, the method of proof can be used in a similar way for other linear approximation methods as well. The norms based on $C$ and $L^{p}, 1 \leqq p<\infty$, can be handled by the same methods. The results are similar up'to different operator norms of the Fourier sum. All estimates are formulated with. explicit constants depending only on parameters of the spaces. Using de la Vallée Poussin means, we establish a Jaclisontype theorem on the best approximation in such Hölder-Zygínund spaces. However, in our general approach it is not possible to prove converse results (see [7] for the. classical Hölder spaces). Introducing some separable subspaces, wé can formulate corresponding "small- $o$ " convergence results. These estimates are of special interest in view of the nonseparability of the usual Hölder-Zygmund spaces.

\section{Definitions and prelininary rèsults}

Let $X$ be one of the nsual spaces $L^{p}(1 \leqq p<\infty)$ or $C$ of $2 \pi$-periqdic complex- valued functions, the norm in $X$ being

$$
\|f\|_{X}= \begin{cases}\|f\|_{p}=\left\{\int_{0}^{2 \pi}|f(x)|^{p} d x\right\}^{1 / p} & \text { if } \quad X=L^{p}, \\ \|f\|_{\infty}=\max _{x \in \mathbb{R}}|f(x)| & \text { if } \quad X=C .\end{cases}
$$

In the following, the value $p=\infty$ will always refer to the underlying space $X=C$. For $k \in \mathbb{N}$, we define the set of modulus-type functions $\Omega^{k}$ as the set of all functions $\omega$ satisfying, the following conditions:

a) $\omega: \mathbb{R}^{+} \rightarrow \mathbb{R}^{+}$. (here $\left.\mathbb{R}^{+}:=[0, \infty)\right)$;

b) $\omega$ is monotonically increasing;

c) $\omega(h) \stackrel{\dot{\rightarrow}}{\rightarrow} \omega(0)=0$ as $h \rightarrow 0+$;

d) $\omega(h) h^{-k}$ is monotonically decreasing.

Given $\omega \in \Omega^{k}$, define the seminorm $\|\cdot\|_{X^{\omega}}$ by

where

$$
\text { - }\|f\|_{X^{\omega}}=\left\lceil\sup \left\{\left\|\Delta_{h}{ }^{k} f\right\|_{X} / \omega(h): h>0\right\}\right.
$$

$$
\Delta_{h}{ }^{1} f(x)=f(x+h)-f(x) \quad \text { and } \quad \Delta_{h}{ }^{k} f=\Delta_{h}{ }^{1} \Delta_{h}{ }^{k-1} f, \quad k \geqq 2 .
$$

In what follows, we will often use the well-known inequalities

$$
\left\|\mathrm{U}_{h}{ }^{k} f\right\|_{X} \leqq\left\{\begin{array}{ll}
2^{k-i}\left\|\Delta_{h}{ }^{l} f\right\|_{X} & \text { if } \quad f \in X \\
h^{k-l}\left\|\Delta_{h}{ }^{l} f^{(k-l)}\right\|_{X} & \text { if } \quad f^{(k-l) \in X}
\end{array} \quad(k \cdot \geqq l),\right.
$$

where $f^{(k-l)}$ stands for the (distributional) $(k-l)$-th derivative of $f$ (see e.g. [15]). We denote by $X^{r, \omega}$ the set of all functions $f$ such that $f^{(r)} \in X$ and $\left\|f^{(r)}\right\|_{X^{\omega}}<\infty$. Note that $X^{r, \omega}$, provided with the norm

$$
\|f\|_{X^{r, \omega-}}=\sum_{j=0}^{r}\left\|f^{(j)}\right\|_{X}+\left\|f^{(r)}\right\|_{X^{\omega}}
$$


is a Banach space. Furthermore, let $\tilde{X}^{r . \omega}$ be the subspace of $X^{r, \omega}$ defined, by

$$
\tilde{X}^{r, \omega}=\left\{f \cdot \epsilon \cdot X^{r, \omega}:\left\|\Delta_{h}^{k} f^{(r)}\right\|_{X} / \omega(h) \rightarrow 0 \text { as } h \rightarrow 0+\right\} .
$$

Notice that this subspace is only of interest in the case where $\omega(h) h^{-k} \rightarrow \infty$ as $h \rightarrow 0+$, because the condition $\left\|\Delta_{h}{ }^{k} f\right\|_{\dot{X}} / h^{k} \rightarrow 0$ as $h \rightarrow 0+$ implies that $f=$ const. The spaces $X^{r, \omega}$. generalize the classical Hölder-Zygmund spaces, in which case $\omega(h)=h^{\beta}$ with $0 \leqq \beta \leqq k$. For $f \epsilon X$ and $n \in \mathbb{N}_{0}$, we define the $n$-th Fourier sum of $f$ by.

$$
S_{n} f(x)=\sum_{k=-n}^{n} f^{\wedge}(k) \cdot \mathrm{e}^{\mathrm{i} k x}
$$

and the $n$-th de la Vallée Poussin mean of $f$ by

$$
\sigma_{n, v} j=\frac{1}{v+1} \sum_{k=n-v}^{n} S_{k} j, \quad 0 \leqq v \leqq n
$$

$\rightarrow$ Furthèrmore, let

$$
E_{n}(f, Y)=\inf \left\{\left\|f-p_{n}\right\|_{Y}: p_{n} \in T_{n}\right\}
$$

where $T_{n}$ is the set of all trigonometric polynomials of degree less than or equal to $u$. 'To prove estimates in Hölder-Zygmund norms we need the following well-known results.

Lemma $\mathcal{C}[15-17]:$ If $f^{(m)} \in X$, then $E_{n}(\dot{f}, \bar{X}) \leqq \frac{\pi}{2}(n+1)^{-m}\left\|f^{(m)}\right\|_{X}$ and, for all $l \in \mathbb{N}$,

$$
E_{n}(f, X) \leqq C_{l}(n+1)^{-m} \sup _{0<h<1 /(n \mp+1)}\left\|d_{h} j^{j(m)}\right\|_{X}
$$

The constant $C_{l}$ can be estimated by,

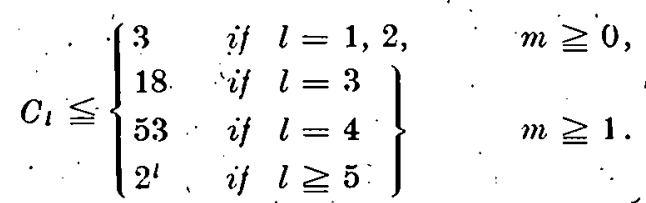

Lemma $2[2,17]$ : The estimate $\left\|f-S_{n} f\right\|_{X} \leqq B_{p} E_{n}(f, X)$ holds with

$$
B_{p}= \begin{cases}2,5+4 \pi^{-2} \ln n & \text { if } 1 \leqq p \leqq \infty \\ 4(p /(p-1))^{1 / p}+2 & \text { if } 1<p<2, . \\ 1 & \text { if } p=2, \\ 4 p^{1-1 / p}+2 & \text { if } 2<p \leqslant \infty\end{cases}
$$

Furthermore,

$$
\left\|f-\tau_{n, v} f\right\|_{x} \leqq 36 \sum_{i=0}^{n+v} E_{i+n-r}(f, X) / v^{i+1}
$$

\section{Approximation by the Fourier sum}

For simplicity of the representation, we here restrict ourselves to the approximation of $f$ by the Fourier sum $S_{n} f$. By the same method of pron one obtains analogous error estimates for interpolatory polynomials on equidistant nodes (see $[9,12])$. 
- Theorem 1: Let $r, m \in \mathbb{N}_{0}, k, l, n \in \mathbb{N}, \omega_{\alpha} \subseteq \Omega^{l}$ and $\omega_{\beta} \in \Omega^{k}$. Assume one of the following two conditions to bersutisfied:

$$
0 \leqq m-r \leqq k-l \text { and } q(h)=h^{m-\tau} \omega_{\alpha}(h) / \omega_{\beta}(h) \text { is monotonically increasing }
$$

(ii) $\quad k \leqq m-r$ (implying that $q(h)$ is monotonically increasing).

Then for $f \epsilon^{\prime} X^{m, \omega}$ we have the estimute

where

$$
\left\|f-S_{n} f\right\|_{X^{r}, \omega_{B}} \leqq D B_{p} q(1 /(n+1)) \sup _{.0<h<1 /(n !-1)}\left\{\left\|\mathcal{L}_{h}^{l} f^{(m)} \cdot\right\|_{X} / \omega_{\alpha}(h)\right\}
$$

$$
D=\left\{\begin{array}{ll}
C_{l} 2^{k+1} & \text { if } k \leqq m-r, \\
\max \left(C_{l} 2^{k+1}, 2 C_{l}+2^{k-m+r-1-1}\right) & \text { if } m-r \leqq k-l,
\end{array} .\right.
$$

or, shorlly,

$$
\left\|f:-S_{n} f\right\|_{X^{r}, \omega_{\beta}^{\prime}}=\left\{\begin{array}{ll}
O(q(1 / n)) & \text { if } 1<p<\infty \\
O(q(1 / n) \log n) & \text { if } p=1 \text { or } p=\infty
\end{array} \quad(n \rightarrow \infty) .\right.
$$

Remarks: 1 . There is a gap $m-r<\dot{k}<m-\dot{r}+l$ in the conditions (i) and (ii) of Theorem 1. To make this clear we quote the following example. Let $m=1, r=0, k=l=2$, $\omega_{\mathrm{a}}(h)=h, \omega_{\beta}(h)=h^{2}$. Then

$$
X^{\gamma, \omega_{\beta}}=\left\{f:\left\|\alpha_{h}^{2} f\right\|_{X}=O\left(h^{2}\right), h \rightarrow 0-1\right\} \subsetneq X^{m, \omega_{\alpha}} \doteq\left\{f: E_{n}(f, X)=O\left(n-\cdot^{2}\right), n \rightarrow \infty\right\},
$$

so that 'Theorem 1 does not make sense.

2. Assertion (2) remãins true, without any restrictions, for all $k, l \in \mathbb{N}, m, r \in \mathbb{N}_{0}, m \geq r+1$, $\omega_{\alpha^{r}} \in \Omega^{l} \cdot \omega_{\beta} \in \Omega^{m-\tau} \cap \Omega^{k}$ and $q$ monotonically increasing. This is an immediate consequence of 'Theorem 1 and the inequality

$$
\sup \left\{\left\|\Lambda_{h}{ }^{k} /(r)\right\|_{X} / \omega_{\beta}(h): h>0\right\} \leqq 2^{k-k^{\prime}} \sup \left\{\left\|A_{h} k^{\prime} j^{(r)}\right\|_{X} / \omega_{\beta}(h): h>0\right\}
$$

if $k^{\prime}<k$ and $\omega_{\beta} \in \Omega^{k^{\prime}} \subset \Omega^{k}$. 'However, in the case $m=r$ we must assume $k \geq l$, in general, because

$$
\left\{f \in X:\left\|\Delta_{h}^{1} \dot{d}\right\|_{X}=O(h), h \rightarrow 0+\right\} \subsetneq\left\{j \in X:\left\|\Delta_{h}^{2} f\right\|_{X}=O(h), h \rightarrow 0+1 .\right.
$$

3. Note that if the conditions formulated in Theorem. 1 or in Remark 2 are fulfilled, then $X^{m, \omega_{\alpha}} \subseteq X^{r, \omega_{\beta}}$

4. Similarly one can find analogous approximation results for the interpolatory polynomial $L_{n} f \in T_{n}$, which interpolates $f$ at equidistant nodes (sece $[9,11]$ ).

- Before proving the theorem we add some simple facts.

Corollary 1. Under the assumptions of Theorem 1 (see also Remark 2) we have, for $f \in \tilde{X}^{m \cdot \omega_{\alpha}}$,

$$
\left\|f-S_{n} f\right\|_{x^{r \cdot \omega_{\beta}}}=\left\{\begin{array}{ll}
o(q(1 / n)) & \text { if } 1<p<\infty \\
o(q(1 / n) \log n) & \text { if } p=1 \text { or } p=\infty
\end{array} \quad(n \rightarrow \infty) .\right.
$$

The following two corollaries illustrate what happens for particular choices of the parameters.

Corolläry 2. Let $\omega_{\alpha} \in \Omega^{2}, \omega_{\beta} \in \Omega^{2}, m-r \geqq 2,2 \leqq p<\infty$ und f $\in X^{m, \omega_{* x}}$. Thèn $\left\|f-S_{n} f\right\|_{X^{r . \omega_{\beta}}} \leqq 120 p q(1 /(n+1))\left\|f^{(m)}\right\|_{X^{\omega_{2}}}$. 
In $[5,6]$ asymptotic estimates are obtained for $\left\|f-S_{n} f\right\|_{\mathscr{e}}$ if $f \in \mathscr{H}^{t}, s<t$, where $\mathscr{H}^{s}$ is the Banach space of all functions $f \in X$ with finite norm

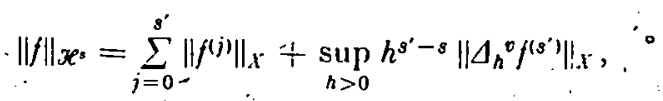

with $s^{\prime} \in \mathbb{N}_{0}, s-1 \leqq s^{\prime}<s, v=1$ if $s \notin \mathbb{N}$ and $v=2$ if $s \in \mathbb{N}$. Except for the case $t \in \mathbb{N}, t-1<s<t$ (where $k:=1, l=2, m=r$ ), Theorem 1 gives good constants for these estimates. In view of ${ }^{\prime}(3)$ it is clear that Theorem 1 does not include this particular case. However, in the special situation of $\mathscr{H}^{\text {s }}$ spaces we can conpute constant by standard methods (see [12]). It is natural that this constant tends to infinity if $t-s$ goes to zero.

- Corollary 3: Let $f \in \mathscr{H}^{t}$. Then, for $t>\cdot s$,

$$
\left\|f \cdot S_{n} f\right\|_{\Re^{e}} \leqq B_{p}(n+1)^{s-t}\|f\|_{\Re^{t}} \cdot \begin{cases}18+12 /\left(1-2^{s-t}\right) & \text { if } t \in \mathbb{N}, t-1<s, \\ 24 & \text { otherwise. }\end{cases}
$$

Proof of Theorem $1:$ Set $H=\{h: 0<h \leqq 1 /(n+1)\}, G=\{h: h>1 /(n+1)\}$. In view of the I,emmas 1 and 2 we obtain for $0 \leqq j \leqq r$ that

$$
\begin{aligned}
\left\|\left(f-S_{n} f\right)^{(j)}\right\|_{X}^{\prime} & \leqq B_{p} E_{n}\left(f^{(j)}, X\right) \\
& \leqq B_{p} C_{l}(n+1)^{j-m} \dot{\omega}_{\alpha}\left(1 /\left(n+\frac{1}{1+} 1\right)\right) \operatorname{sip}\left\{\left\|A_{h}^{l} f(m)\right\|_{X} / \omega_{a}(h): h>0\right\},
\end{aligned}
$$

where we have used that $S_{n} f^{(j)}=\left(S_{n} f\right)^{(i)}$. Hence, by summation, we find that

$$
-\sum_{j=0}^{r}\left\|\left(f-S_{n} f\right)^{(i)}\right\|_{X} \leqq 2(n+1)^{r-m} B_{p} C_{l} \omega_{a}\left(\frac{1}{n+1}\right) \sup _{h \in H} \frac{\left\|\Delta_{h}^{l} f^{(m)}\right\|_{X}}{\omega_{\alpha}(h)} .
$$

To estimate the second term of the norm we split the supremum into two parts. First write

$$
A:=\sup _{h \in \| !}\left\{\left\|\mathcal{L}_{h}{ }^{k}\left(f-S_{n} f\right)^{(r)}\right\|_{Y} /()_{\beta}(h)\right\} \leqq B_{p} \sup _{h \in H}\left\{E_{n}\left(\mathcal{L}_{h}{ }^{k} f^{(r)}, X\right) / \omega_{\beta}(h)\right\}
$$

If.condition (i) is fulfilled, then

$$
\begin{aligned}
2 E_{n}\left(\Delta_{h}{ }^{k} f^{(r)}, X\right) & \leqq \pi\left\|\Lambda_{h}{ }^{k} f^{(r)}\right\|_{X} \leqq \pi \|\left\langle\left\|_{h}{ }^{k-m+r} f^{(m)}\right\|_{X} h^{m-r}\right. \\
& \leqq \pi 2^{k-m+r-l / h^{m-r}}\left\|L_{h} f^{(m)}\right\| x
\end{aligned}
$$

which gives that

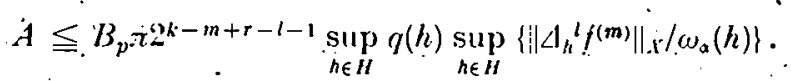

Let now $k \leqq m-r$. Using Lemma 1 once more and taking into account that. $\Delta_{\delta}{ }^{l} \Delta_{h}{ }^{k} f=\Delta_{h}{ }^{k} \Delta_{o}{ }^{l} f$, we get

$$
\begin{aligned}
& E_{n}^{\prime}\left(\Delta l_{h}{ }^{k} f^{(\tau)}, X\right) \leqq C_{l} \sup _{\delta \in H}\left\|\Lambda_{h}{ }^{k}{ } L_{\delta}{ }^{l} !^{(m-k)}\right\|_{X}(n+1)^{r+k-m} . \\
& \therefore \leqq C_{l}\left(x^{\prime}+1\right)^{\mathrm{r}+k-m} h^{k} \sup _{\delta \in H}\left\{\left\|\backslash_{\delta}^{l} f^{(m)}\right\|_{\mathrm{I}} / \omega_{\alpha}(\delta)\right\} \sup _{\delta \in H} \omega_{\alpha}(h) .
\end{aligned}
$$

Hence,

$$
A \leqq B_{p} C_{l}(n+1)^{\gamma-m} \omega_{\beta}\left(\frac{1}{n+.1}\right)^{-1} \omega_{\alpha}\left(\frac{1}{n+1}\right) \sup _{x \in H}\left\{\left\|\Delta_{\delta}^{l} f^{(m)}\right\|_{X} / \omega_{\alpha}(\delta)\right\} .
$$

Combining this estimate and (6) jo obtain

$$
A \leqq B_{\nu} C_{: q}\left(\frac{1}{i+1}\right) \sup _{h \in H} \frac{\left\|\Delta_{h}{ }^{l} f^{(m)}\right\|_{x}}{\omega_{a}(h)} \cdot \begin{cases}\pi 2^{k-m+l^{-l-1}} & \text { if } m-r \leqq k-l, \\ C_{l}- & \text { if } k \leqq m-r .\end{cases}
$$


1 The case $h \in G$ can be handled in a similar way. This gives

$$
\begin{aligned}
& \sup _{h \in G}\left\{\left\|\Delta_{h}{ }^{k}\left(f-S_{n} f\right)^{(r)}\right\|_{X} / \omega_{p}(h)\right\} \leqq B_{p} 2^{k} \sup _{h \in(i}\left\{E_{n}\left(f^{(r)}, X\right) / \omega_{\beta}(h)\right\} \\
& \leqq B_{p} 2^{k} C_{l}(n+1)^{r-m} \omega_{\beta}\left(\frac{1}{n+, 1}\right)^{-1},\left(\omega_{a} \cdot\left(\frac{1}{n+1}\right) \sup _{h \in H}:\left\{\left\|\Delta_{h}{ }^{\prime} f^{(m)}\right\|_{X} / \omega_{n}(h)\right\} .\right.
\end{aligned}
$$

Putting together (4) with the last two estimates we arrive at the assertion

\section{0}

\section{4: Best approximation}

By, a well-known result of BARI and STECKIN [1], the properties

$$
E_{n}(f, X)=' O(\omega(1 / n))(n \rightarrow \infty) \quad \text { and } \quad\left\|\Delta_{h}{ }^{k} f\right\|_{X}=O(\omega(h)) \cdot(h \rightarrow 0+1)
$$

' are equivalent if and only if $\omega \in \Omega^{k}$ satisfies the estimate'

$$
1<\varliminf_{h \rightarrow 0+} \omega(c h) / \omega(h) \leqq \varlimsup_{-h \rightarrow 0+} \omega(c h) / \omega(h)<c^{k}
$$

for some $\dot{c}$. By this reason we do not try to characterize the best approximation in $X^{r}, \omega_{\beta}$ for the general choice of $\omega_{a}^{\cdot}$ and $\omega_{\text {.. }}$. However, with the help of the de la Vallée Poussin imeans of $f$ we can remove the $\log n$ term in the estimates. Then we obtain an order of convergence which is best possible at least for $\omega_{a}$ and $\omega_{j}$ from some subclasses of $\Omega^{l}$ and $\Omega^{k}$ containing $\omega_{a}(h)=h^{a}, \omega_{\beta}(h)=h^{\beta}, 0<\beta<k, 0<\alpha<l$.

Lem ma: Under the assumptions of Theorem 1 we have

$$
\left\|f-\bar{\sigma}_{n, v} f\right\|_{\mathcal{K}^{\tau, \omega_{\beta}}} \leqq 36 D \sum_{i=0}^{n+v} \frac{1 ;}{v+i+1} q\left(\frac{1}{i+n-v+1}\right) \sup _{0<h<1 /(n) i+1)} \frac{\left\|\Delta_{h}^{l} f^{(m)}\right\|_{x}}{\omega_{a}(h)} .
$$

For $q(h) h^{-r}<C$, a simple calculation yields that

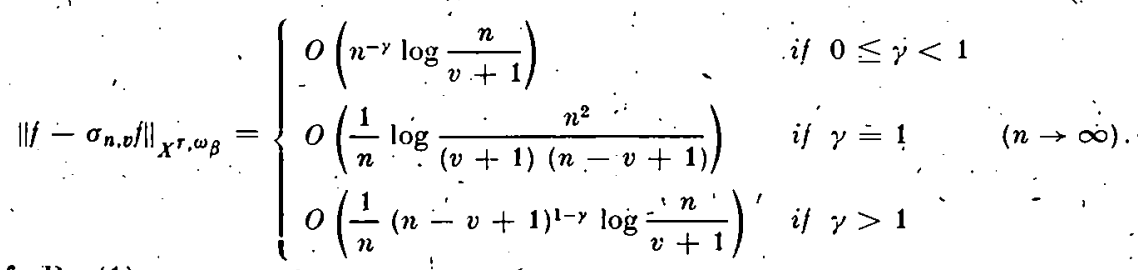

Proof: By (1),

$$
\left\|f-\sigma_{n, v} f\right\|_{X^{r, \omega_{\beta}}} \leqq 36 \sum_{i=0}^{n+v} \frac{1}{v+i+1}\left(\sum_{j=0}^{r} E_{i+n-v}\left(f^{(i)}, X\right)+\sup _{h>0} \frac{E_{i+n-r}\left(\Lambda_{h}{ }^{k} f^{(r)}, X\right)}{\omega_{\beta}(h)}\right) .
$$

Estimating the terms in the parantheses in the same way as ${ }^{i}$ in (4), (5); (7) and (8), gives the assertion immediately

"To have the best possible order of convergence let $v=[n / 2]$. Using that $q(2 / n)$ $\leqq 2^{r-m+k} q(1 / n)$, we obtạin the following theorem.

Theorem 2: Assume the conditions of Theorem 1 , ure fulfilled. Then

$$
k_{n}\left(f, X^{r, \omega_{\beta}}\right) \leqq 108 \cdot 2^{r-m+k} D q(1 / n)\left\|f^{(m)}\right\|_{X^{\omega_{\alpha}}} .
$$

In particular, if $j \in \tilde{X}^{m, \omega_{\alpha}}$, then

$$
E_{n}\left(f, \dot{X}^{r, \omega o}\right)=o(q(1 / n)), \quad n \rightarrow \infty .
$$

From the last result it follows immediately that the spaces $\tilde{X}^{m, v_{\alpha}} \dot{a r e}$ separable for any choice of u. $\in \Omega^{\prime}$. 


\section{REFERFNCES}

[-1] БАРи, Н. К., и С. Б. СТЕчнин: Нанлучшие приближения и дифференциальные свойства двух сопряжениых функций. Труды Моск. мат. о-ва ј (1956), 483-522.

[2] Дамен, В.: О паплучшем приближении и суммах Валле Пуссена. Мат. заметки 23 (1978), 671-68:.

[3] Kвотоу, V. G.: Note on the convergence of Fourier series in the spaces $\Lambda_{\omega}{ }^{p} \cdot$ Acta Sci. Math. 41 (1979), 335-338. .

[4] Leminder, L.: Generalizations of Prößdorf's theorems. Studia Sci. Math. 14. (1979), $431-439$.

[5] McLean, W., Prössdorf, S., and W. L. WEndlasd:'Pointwise error estimates for the trigonometric collocation method applied to singular integral equations and periodic pseudodifferential equations. J. Int. Equ. Appl. 2, 1 (1989), 1-22.

[6] McLeax, W., and W.L. Wendeaxd: Trigonometric approximntion of solutions of periodic pseudodifferential equations. In: Operator'Theory: Advances and Applications, Yol. 41, Basel: Birkhäuser. Verlag 1989, p. 359-383.

[7] Prestin, J.: Best approximation in Lipschitz spaces. In: Coll. Math. Soc. Jan. Bolyai 49: Alfred Haar Memorial Conference. Proc. Conf., Budapest (Hungary) 1985 (Eds.: J. Szabados and K. Tandori). Budapest: Jan. Bol. Math. Soc. 1987, and Amsterdam-Oxford-New York: North-Holland Publ. Co. 1987, p. 753-759.

[8] Prestin, J.: On the approximation by de la Vallée Poussin sums ánd interpolatory poly: nómials in Lipschitz norms. Analysis Math. 13 (1987), $251-259$.

[9] Prestis, J.: Trigonometric interpolation in Hölder spaces. J. Approx: Theory 53 (1988), $145-1 j 4$

[10] Prössporf, S.: Zur Konvergenz der Fourierreihen hölderstetiger Funktionen. Math. Nachr. 69 (1975), 7-14.

[11] Prössborf, S., and B. Silb frmasx: Projektionsverfahren und die näherungsweise Lösung singúlärer Gleichungen (Teubner-Texte zur Mathematik: Bd. 14). Leipzig: B. G. 'Teubner Verlagsges. 1977.

[12] Prössporf, S., and B. Silbermanx: Numerical analysis for integral and operator equa: tions. Berlin: Akademié-V'erlag/Basel-Boston-Stuttgart: Birkhäuser Verlag 1990.

-[13].SiCK EL, W.: Some observations on equivalent quasi-norms in generalized Besov spaces and ipproximation of functions in Lipschitz norms. Preprint. Jena: Friędrich-Schiller-Universitiit, Preprint $\mathbf{N} / \mathbf{8 6 / 4 9 .}$

[14] Stypíski, Z.: Generalization of the theorem of Prößdorf. Funct. Approx. Comment. Math. 7 (1979), $101-104$.

[15] Тимн, А.Ф.: Теория приближения функцй действтельного переменпого. Москва: Физматгиз 1960 .

[16] Жук, В. В.: О точности представления непрерывной $2 \pi$-периодичесноп функции при помощи линейніхх методов аппроксимации. Нзв. высш. уч. зав. 123 (1972) 8 , $46-59$.

[17] Zyamuñ D, A.: Trigonometric Series. Vols. 1 and II. London: Cambridge Univ. Press 1959.

Manuskripteingang: 24.04. 1989.

\section{r VERFASSER :}

Dr. Jüroex Prestin

Sektion Mathematik

der Wilhelm-Pieck-Universität ।

Universitätspl. 1

DDR - 2500 Rostock
Prof. Dr. Siegraied Prössdori .

Karl-WeierstraB-Institut

für Mathematik der AdW der DDR

Mohrenstr. 39

DDR - 1086 Berlin 